\title{
Boundary Problems: Reclaiming Thought Space in the Attention Economy
}

\author{
EMILY BAKER \\ University of Arkansas
}

\begin{abstract}
There is far less opportunity for thought that is not in some way mediated than there once was, and often this is by design. Cognitive engineers ply vast resources to attract and retain our attention toward what are ultimately commercial ends. They use pervasive and spatially unbound mediating technologies to gain access to every space in our lives. In this information superabundance, the act of filtering desirable content induces such a cognitive load that we are left with noticeably altered brains-eroded attention spans, failing memories, diminished executive function and complex reasoning skills, etc. These lead to a host of issues relating to health and wellbeing including sleep deficiencies, social isolation, depression and anxiety. In light of the pressures of this new attention economy, what role does architecture have to play in the reclamation of thought-space and embodied experience in contemporary life, particularly in the home? This paper will present some preliminary design ideas for dwellings that address the attention economy, drawing boundaries around behavior-altering technologies in order to foster long-term desires for health, mental clarity, focus, restfulness, and social connection rather than the typical focus on immediate comfort. This is not a Luddite plea to leave these advancing technologies behind, but a humanist plea to find the boundaries in which we can thrive while using them.
\end{abstract}

Eighty people attending a stargazing event at the McDonald Observatory in west Texas were asked to refrain from the use of their phones, even for a second, as they sat outside with no artificial lighting waiting 45 minutes for their eyes to adjust to the dimness of the night. It was only then that they were able to access a way of seeing that allowed them to observe hundreds of stars coalescing into the Milky Way and Murcury and Venus sitting just above the horizon, thus situating them in the solar system and the galaxy in a way hardly ever done by modern humans. Had anyone looked at a phone or turned on a light for just a second, they would have lost this way of seeing, this orientation. In this case, a boundary was placed on mediating technologies (artificial lighting and phone screens) in order to access a mode of perceiving-a mode of being - that was otherwise out of reach.

Marshall McLuhan notably referred to technologies as extensions of our bodies and faculties. ${ }^{1}$ These extensions allow us to access unique modes of being and perceiving. In a world of pervasive mediation, could a boundary around a mediating technology be just as powerful of an extension? This paper will discuss boundaries of various types and their role in architecture and the urban environment as tools (new instrumentalities) to provide access to modes of being and wellbeing that are no longer automatic in contemporary life, and it will propose initial ideas for dwellings designed for this context.

\section{COGNITIVE COSTS}

Mounting evidence suggests that the functioning of our brains is being altered by the current superabundance of information in our environments. Attention deficit trait (ADT), an environmentally induced version of ADD, is one of several effects, causing disruption to work and home life and leading to anxiety, depression, sleep deficiencies, poor reasoning skills and diminished executive function. ${ }^{2}$ While the aim of this paper is not to decry any of the remarkable technologies available today, this change merits consideration. There is generally much less opportunity for thought that is not in some way mediated than there once was. Often this is by design, because while the commodification of attention is not a new phenomenon (consider advertising on a public square), it has never been so spatially unbound, and thus so difficult to avoid. ${ }^{3}$ The so-called attention economy plies massive amounts of resources for cognitive engineering to attract and retain our attention (essentially our thoughts) through multiple digital platforms, or mediating technologies.

By adapting to the current speed and amount of available information, our brains, and by extension our bodies, are losing the propensity for certain modes of thinking and being. There has been an erosion of ability to focus (to get into a focused state and to maintain it) and a loss of the "space" for free or meandering, unmediated thought. These losses have effects that range from increased anxiety, decreased creativity, decreased productivity, decreased ability to consider nuance and a propensity toward simplistic conclusions, lack of self-discipline, poor emotional regulation, and the list goes on. As well, the developed world struggles with sleep deficiencies that bring on a host of other health and wellbeing problems.

This is not an architectural problem per se, but there could be architectural implications. What role might architecture play in a reclamation of thought-space in light of the pressures of the attention economy, and how can architecture help adopt a new sensibility about how to live well with tech?

Malcolm McCullough talks about the current superabundance of information and its effect on people in their environments in his book Ambient Commons. His succinct 


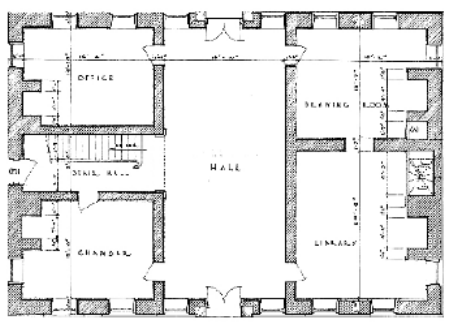

COLONIAL, 17th-19th century

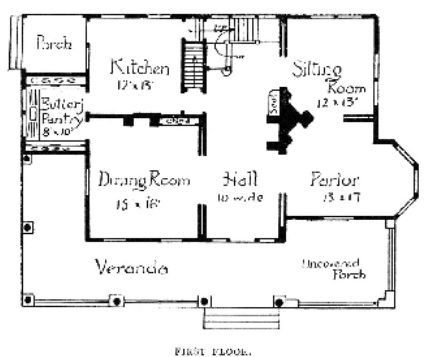

VICTORIAN, 1880-1910

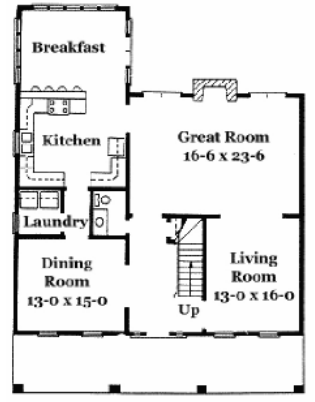

COLONIAL REVIVAL, 1895-1940

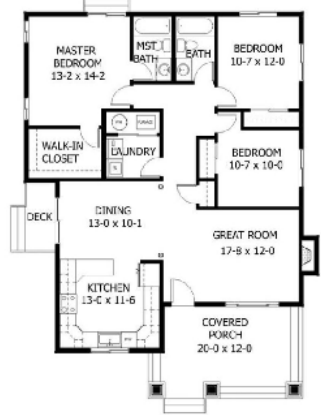

AMERICAN BUNGALOW. 1900-1930

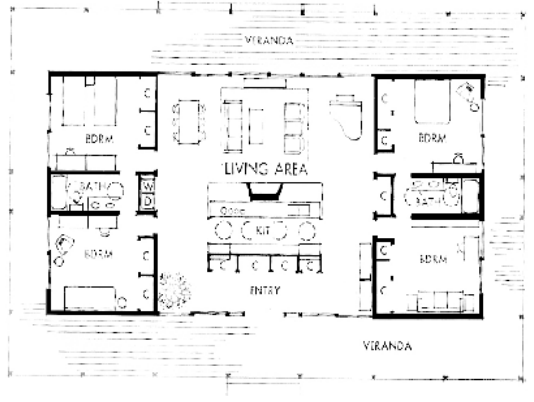

MID-CENTURY MODERN, 1930s-1960s

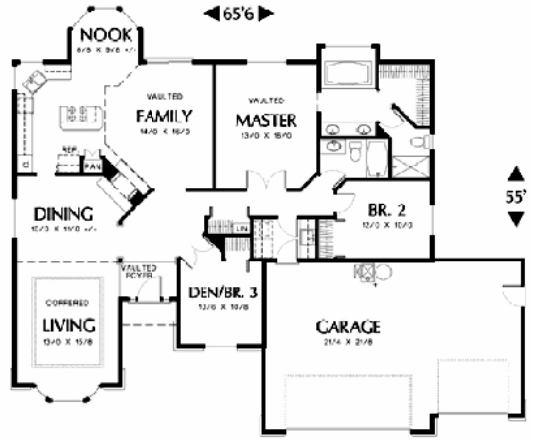

NEO-ECLECTIC, 1970s-present

Figure 1: American house plans from mid-1800s to present ${ }^{6}$

discussion posits that an understanding of the experience of an environment must be thought of as the combined experience of physical embodiment and mediated perception in/ of a particular space. ${ }^{4}$ Are we designing for such dual experiences-for what he calls the "takeoffs and landings," or the transitions in and among embodied experiences and interaction with mediating technologies? If not, are we conceding architectural territory?

\section{EVOLUTION OF CONTEMPORARY DWELLINGS}

Dwellings are the places most charged with providing for wellbeing, so they are the primary focus of this work. Spaces of dwelling have always adapted as new technologies emerge. A survey of the history of residential plans from the United States reveals how dwelling design has evolved since the introduction of electricity into homes. This diagram shows American houses from the mid-1800s to the present (figure 1) adapting to increased access to electricity, lighting, air conditioning, and advances in kitchen technologies. Simultaneously, of course, they are adapting to societal changes as well-some of these precipitated by the aforementioned technologies. The plans show a typical dwelling more and more saturated with lighting, electronics, and communication devices. The progression has been toward greater access to these mediating technologies, and they exist in homes essentially unbound. In fact, building codes and regulations codify much of this, requiring electrical outlets spaced at regular intervals in each room. ${ }^{5}$
STANDARD OF COMFORT VS. STANDARD OF WELLBEING

These spatially unbound mediating technologies evidence dwelling design that has evolved to accommodate a "standard of comfort," meaning that short term desires are met immediately. Lighting is available when it is dark, temperature can be controlled at will, and a network provides instant access to information, communication and media. This organization sets comfort as the highest aim. How might our dwellings be reordered if instead of a "standard of comfort" we aim for a "standard of wellbeing" that seeks to satisfy long-term desires for health, mental clarity, focus, restfulness, social connection, and the space for unmediated thought? Without espousing a Luddite attitude of distrust, design can provide an avenue for greater balance or choice about when and how we use mediating technologies that profoundly alter our experience of the world. It is possible to embrace advancing technology while simultaneously seeking thoughtfulness and care in its use.

\section{EXISTING FORMS AND USEFUL BOUNDARIES}

There are two existing forms that are useful in setting up this work. The first is the public park, which represents one way that we have collectively chosen to bind commercial interests spatially so that a different mode of being in the city may be accessed. The image of Central Park (figure 2) shows the physical manifestation of this boundary in New York City. In describing the history of the urban park, Galen Cranz indicates 


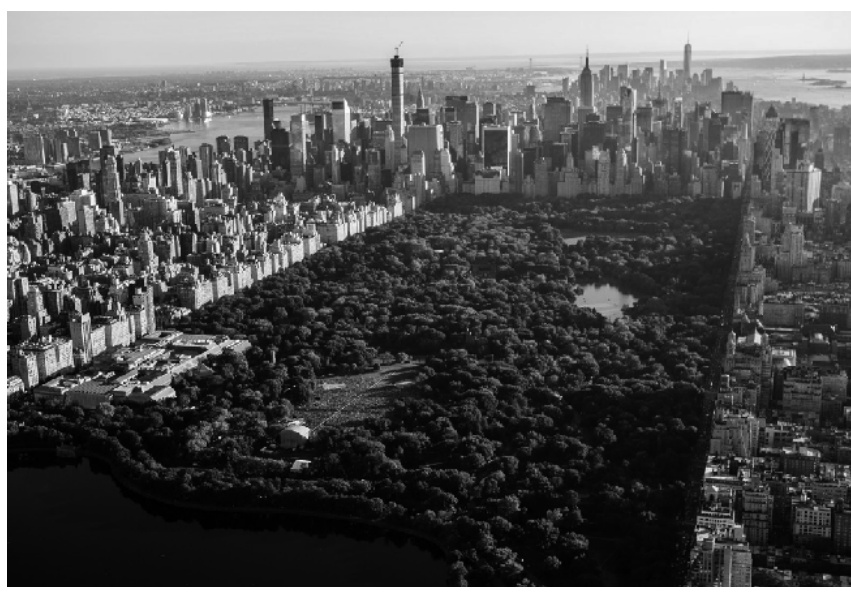

Figure 2: Aerial of Central Park - New York City ${ }^{9}$

that parks, as we now know them, were rooted in the desire to provide workers in an industrializing society with "relief from the rigors of their jobs" because "time-off, leisure, and contemplation was no longer intertwined with work."7 The spatial boundaries that society has accepted within the urban environment to create parks have seldom ${ }^{8}$ been applied to the networked environment, and thus the effects of the attention economy are generally spatially unbound. The urban park offers a useful example of a type of successful and accepted collective boundary on commercial interests which allows an altered mode of being within the built environment.

The second useful form is that of the retreat, or secondary dwelling. The retreat evidences a recurrent desire for unmediated thought-space and embodied experience, whether communal or individual. Retreats are often more primitive than primary dwellings (figure 3)-more remote and less connected via common forms of communication. While at a retreat, inhabitants are more likely to embrace what would be thought of as inconveniences in their daily lives as quaint experiences and opportunities for reflection. Drawing water from a well or tending a fire take on new worth in this context. A recent exhibition at the Fondazione Prada entitled Machines À Pencer curated by Dieter Roelstraete reflected on "the correlation between conditions of exile, escape and retreat and physical or mental places which favor reflection, thought and intellectual production." ${ }^{10}$ Reduced scale reproductions of the primitive huts in which philosophers Martin Heidegger and Ludwig Wittgenstein did much of their productive thinking and writing were constructed inside the gallery along with works by artists that draw inspiration from these spaces of reflection-these thought-spaces. The curator points out, "their huts have proven to be an inexhaustible source of inspiration... for generations of artists, attracted to the fantasy of withdrawal as articulated in its most elemental architectural form." The act of withdrawal to a retreat is associated with inspiration and creative production. Withdrawal in a hyperconnected world will require more than physical remoteness. This work will consider ways in which not just secondary, but primary dwellings can offer a form of retreat from constant connectivity and the attention economy. Withdrawal under these circumstances will require a different configuration of boundaries.

A dwelling is at its essence a collection of boundaries. By definition a dwelling, or shelter, is there to protect inhabitants from the elements, provide security, permit selective access, and mitigate light and sound. It does so through various types of boundary conditions, each designed for a specific type of permeability and exclusion. Various boundary conditions permit various modes of dwelling, which in turn foster various modes of being.

This work applies the notion of useful boundaries to those elements of networked life that when unbound, may impede wellbeing. Could the organization of the primary dwelling begin to provide greater balance or control over spent attention? The following two diagrammatic design ideas seek to craft boundaries around certain mediating technologies in order to facilitate distance from unwanted sources of distraction and preserve the space for unmediated thought.

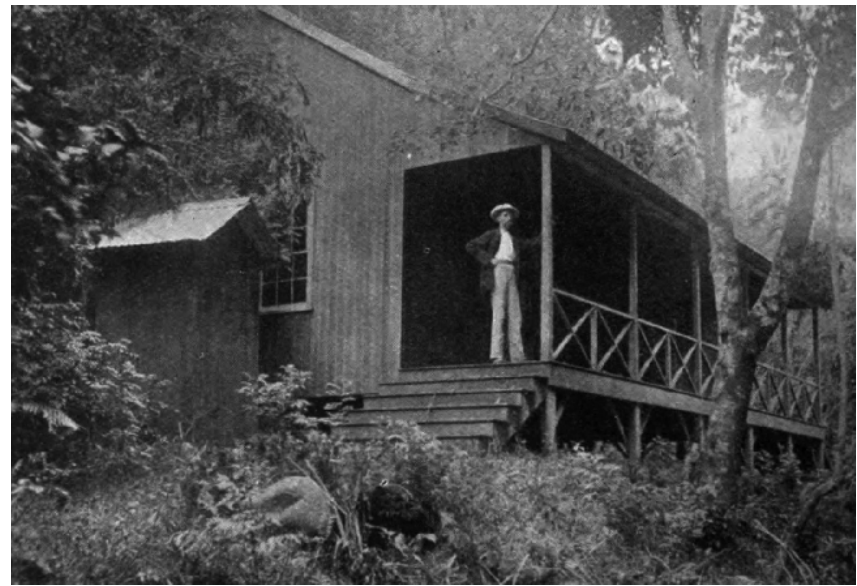

Figure 3: Example of a remote retreat ${ }^{11}$

\section{DESIGN STRATEGIES}

The first of two dwelling proposals employs a strategy of condensing and containing. In contrast to a typical dwelling, here all of the electrical devices-the outlets, appliances, computers and lighting-are condensed into one portion of the dwelling, termed here the Plug. The condensed and separate nature of the Plug encourages intentional use. The rest of the house is left free of these systems and is here called the Shed. The transitional zone between the Plug and the Shed is of particular importance because it prompts the user to make an effort to transition mentally as well as physically. Situating certain activities and devices spatially will provide a greater degree of awareness and choice in their use. 

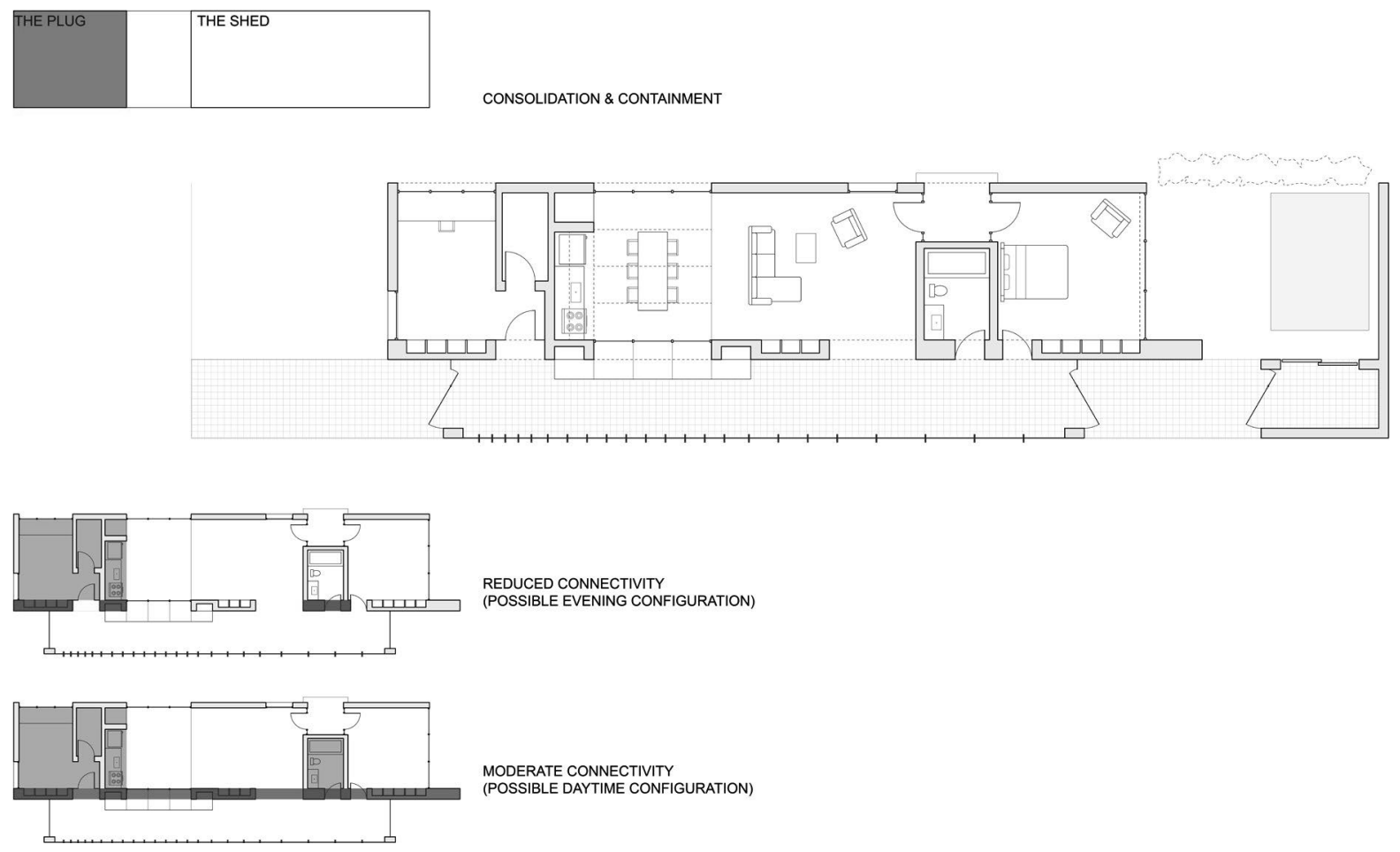

Figure 4: Dwelling Proposal 01

Obviously, the point of wi-fi, laptops, smart phones or similar devices is that they are spatially unbound. This exposes one of the necessary elements of this design proposal-that the user be willing to make conscious tradeoffs between the use of these devices anywhere in the home and access to alternative patterns of habitation that certain boundaries can foster. This configuration offers an alternative equilibrium in patterns of habitation. This is home as retreat, or even as sanctuary, and some degree of ritual must become part of inhabitation in order for it work well. The ceremonial shedding of devices happens here in the transitional zone, just as in some houses people take off their shoes.

The Shed is for rest and communion with others and with self. It offers the space for free or focused thought. The absence of artificial lighting promotes adaptation to natural daily and seasonal rhythms. It allows biological systems for sleep regulation to align with natural cycles, resetting circadian rhythms. ${ }^{12}$ In some climates, the Shed might be free of mechanical systems. Other climates might warrant HVAC systems that create less extreme temperature differentials. ${ }^{13}$ Thermally active surfaces can provide temperature control without the noise and extreme temperature shifts of conventional air conditioning. Allowing some of the temperature shifts through the day and year to be felt on the interior of the dwelling can foster awareness of weather cycles. All this aids in creating a home that promotes embodied experience, or situated cognition. While the aim isn't energy reduction, this is a coincidental positive effect.
Just as designers employ active and passive strategies toward energy efficiency, they might employ active and passive strategies for dealing with mediating technologies. Passive strategies are those that are inherent in the organization and structure of the design. The Plug and Shed organization described above, where part of the dwelling is fully free of electric devices, is an example of a passive strategy. Active strategies would entail designing mediating technologies that demand less of our cognitive capacity, increasingly running in the background instead of the fore-becoming the ambient as Malcolm McCullough has discussed through the lens of interaction design in Ambient Commons. ${ }^{14}$ An active variant of the dwelling described above would employ a mediating spine that allows for use of certain tech in certain spaces during certain parts of the day, creating a cyclical spectrum of use (figure 4 ).

The second dwelling proposal expands the central transitional zone, borrowing the idea of a grand hall from earlier house types. The central hall allows each connecting room to act as either mediated or unmediated space while providing connection and transition between them. Two spines flank the central hall, one a threshold into commonly networked and electrified spaces and the other a threshold into spaces of retreat (figure 5). A more active variant of this proposal uses the notion of inherent information to encode a space with a series of display thresholds. These thresholds, set within the two spines bordering the central hall, would in some way notify the occupant of the current state of the space 


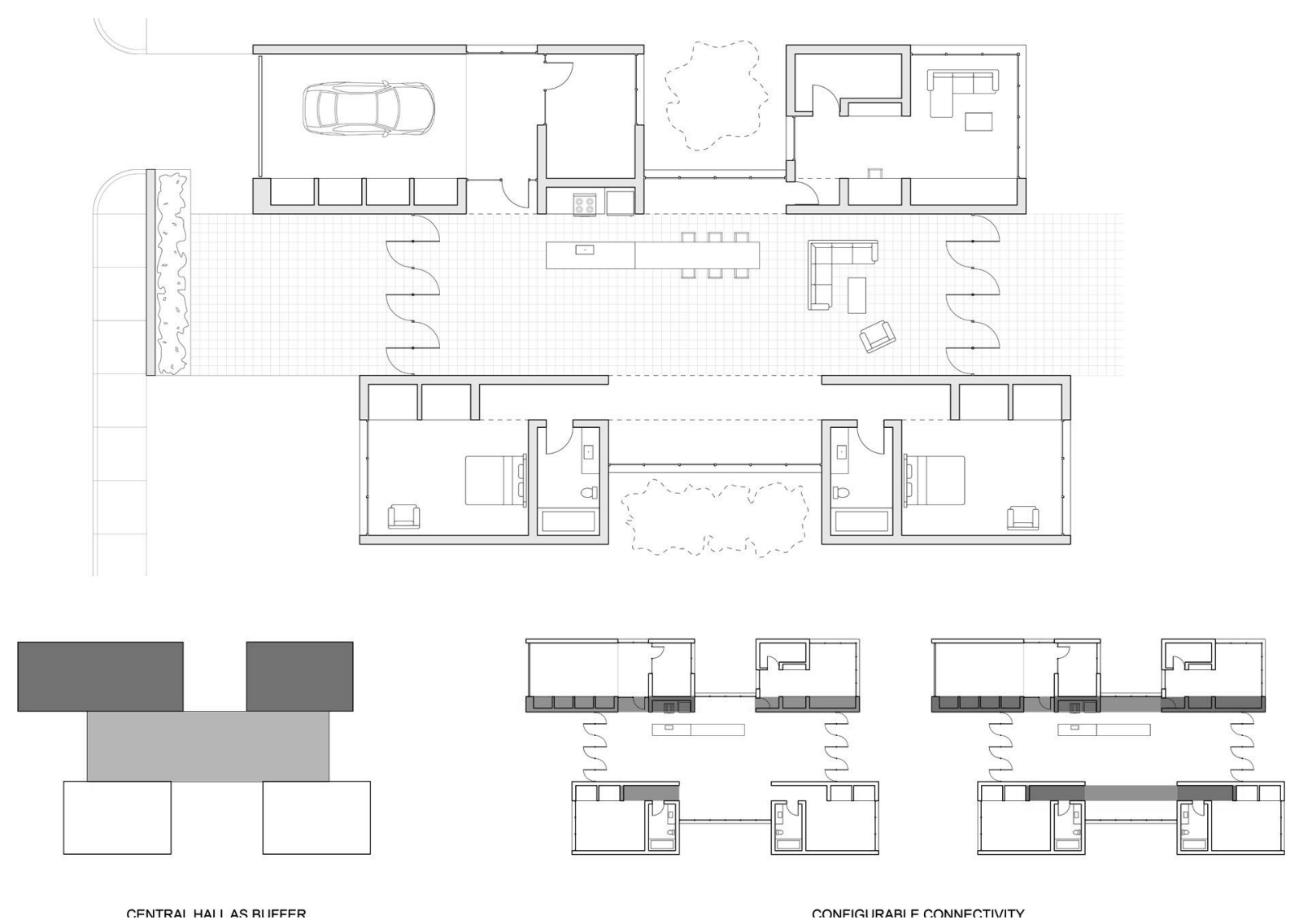

Figure 5: Dwelling Proposal 02

beyond-a visual or non-visual sensory input might indicate whether a room is currently set for more or less networked activity. These thresholds could also activate a certain mode on personal devices that allow only limited use of the device in that space. For example, beyond this threshold one might be able to listen to streaming music but not access email or social media, so that certain functionality becomes spatial dependent while in the home

\section{CONCLUSION}

These preliminary ideas about addressing the attention economy in architecture are not answers but provocations. Architects have a role to play in designing for embodied experience, designing for mediated experience, and designing for the transitions in and among these modes. As we continue to evolve our technologies, this is a call to embrace them an continue to strive to live well with them.

\section{ENDNOTES}

1. Marshall McLuhan, Understanding media: The extensions of man (New York: McGraw-Hill, 1964), 19.

2. Torkel Klingberg, The overflowing brain: Information overload and the limits of working memory (New York; Oxford: Oxford University Press, 2008)

3. Tim Wu, The attention merchants: The epic scramble to get inside our heads (New York: Alfred A. Knopf, 2016)
4. Malcolm McCullough, Ambient commons: Attention in the Age of Embodied Information (Cambridge, Mass.: The MIT Press, 2015) 88-92.

5. NFPA 70: National Electrical Code (Quincy, Mass.: National Fire Prevention Association, 2017)

6. Jessica H. Foy and Thomas J. Schlereth. American Home Life, 1880-1930 (Knoxville: The University of Tennessee Press, 1992)

7. Galen Cranz, The Politics of Park Design: A History of Urban Parks in America (Cambridge, Mass.: The MIT Press, 1982)

8. Michael J. Gaynor, "The Town Without Wi-Fi," The Washingtonian, website, January 2015. Accessed June 2018. https://www.washingtonian. com/2015/01/04/the-town-without-wi-fi/

9. Anthony Quintano, "Global Citizen Festival Central Park New York City from NYonAir," Sept 2014. Accessed June 2018. https://www.flickr.com/photos/ quintanomedia/15351915006

10. Machines À Penser, exhibition (Fondazione Prada, 2018) http://www.fondazioneprada.org/project/machines-a-penser/?lang=en

11. Clement Lindley Wragge, "The Governor's Retreat in the Upper Fautaua Gorge," unknown. Accessed June 2018. https://commons.wikimedia.org/ wiki/File:The_Governor\%27s_Retreat_in_the_Upper_Fautaua_Gorge,_by Clement_Lindley_Wragge.jpg

12. Charles A. Czeisler, "Perspective: Casting Light on Sleep Deficiency," Nature: International Journal of Science 497 (2013), https://www.nature.com/ articles/497S13a.pdf

13. Francis Anderton, "iT House, Joshua Tree," Dwell.com, website (February 2009), https://www.dwell.com/article/it-house-joshua-tree-b04b8a5a

14. McCullough, Ambient commons, 7-24 